\title{
Prevalence of Road Traffic Accident (Non-fatal) in Children: Retrospective Study at Tertiary care Centre
}

\author{
Authors \\ Dr Chandra Shekhar Waghmare ${ }^{1}$, Durgesh Nandani Waghmare ${ }^{2}$, Dr R.K. Chaturvedi ${ }^{3}$ \\ ${ }^{1}$ Assistant Professor, Department of Forensic Medicine \& Toxicology, Gajra Raja Medical College, Gwalior \\ ${ }^{2}$ Yoga Course .Department of Yogic Sciences, LNIPE, Gwalior \\ ${ }^{3}$ Professor \& Head, Department of Forensic Medicine \& Toxicology, TSM Medical College, Lucknow \\ *Corresponding Author \\ Dr Chandra Shekhar Wagmare \\ Email: Drshekharr05@gmail.com, Mob No-9424678980
}

\begin{abstract}
Fatal and Non-fatal road traffic accident in childhood contribute significant public health problem in world. As children grow and their path extends from home to world, they are exposed to hazards and risks. The fatalities from Road Traffic Accidents constitute a major cause of unnatural deaths among children in India. The present study observed that most of road injury fatalities in children involved males in the age group of 5-15 years, most commonly affected were travellers in two wheelers. The present study found that the maximum number of casualties occurred between 8 am -12 Noon which is comparable with findings of other parts of India. Most schools close after $4 \mathrm{pm}$ therefore comparatively more children are present on the road at this time of the day thereby increasing their exposure to automobiles. One of the best ways to do it is to include road safety issues in school curriculum. Those children who ride bicycles should be made to wear helmets as it is expected to reduce the severity of injury to the head. Drivers should avoid talking on mobile phones while on roads.
\end{abstract}

Keyword: Children, Road Traffic Accident, Tertiary Care centre.

\section{Introduction}

Fatal and Non-fatal road traffic accident in childhood contribute significant public health problem in world. As children grow and their path extends from home to world, they are exposed to hazards and risks ${ }^{(1)}$. Despite the fact that children use roads as pedestrians, cyclists, motorcyclists, vehicle passengers but the road environment is rarely developed with involvement of their needs and activities. At global level, road traffic injuries are one of the leading causes of death from unintentional injury, with the highest rates among
15 to 19 years age group of children and a major burden on the world's economy causing a yearly loss of about 518 billion dollar ${ }^{(2)}$.

The fatalities from Road Traffic Accidents constitute a major cause of unnatural deaths among children in India. The Epediomological data of Road Traffic Accidents concern with children are lacking in our country. It is also the foremost cause of unnatural deaths in children, contributing to an annual loss of more than 260,000 lives in the $0-19$ year age group ${ }^{(3)}$. 
India contributes one-sixth of the world's population, $29.5 \%$ of which belongs to the 0 14 year age group. India has witnessed a 10-fold increase in the number of fatalities from 1970 to 2009 with one accident occurring every minute and one fatality every four minutes ${ }^{(4)}$. It has been reported that road traffic injuries are the second most frequent cause of death in the 5-14 year age group in India ${ }^{(4)}$. In 2015 alone, more than 400 children were killed in school bus related incidents; thousands were injured in car, motorbike and pedestrian accidents. According to data from the National Crime Records Bureau, 15,633 children were killed in road accidents across India in 2015, that is nearly 7 times more deaths caused due to road accidents than crimes against children like murder and foeticide ${ }^{(5) .}$.

Overpopulation, increased number of vehicles on roads, poor road conditions and disregard for traffic rules and regulations are major contributing causes of increased injuries and fatalities in India. Hence the present study was carried out to provide a basic baseline data to policy makers to plan for safer transportation routes and in setting up of health care facilities considering trauma in areas that report a higher number of accidents and injuries.

\section{Material Method}

The present study is a retrospective analysis of case details of 183 children who admitted in Causality department of GRMC Gwalior, India from period of Ist June 2015 to $31^{\text {st }}$ May 2016. This institute provides tertiary care to the people of more than half a dozen neighbouring district of central India. Data were collected from In Patient Registers and case sheets of all 183 cases from medical record section of centre. In this study children of age group 1 to 18 years are included who are admitted for RTA with various types of non-fatal injuries.

The information regarding age and sex distribution, rural and urban distribution, time of the accident, non-fatal injury effecting to various body parts and organs and other socio demographic parameters were included under this study. Injuries were divided in to simple and complicated depending on requirement of surgical interventions, and simple injuries are defined as an abrasion that do not require intensive care or surgical interventions, and those which require intensive care of wound like suturing under anaesthesia, fractures, intracranial injuries, head injuries, lacerated facial injuries etc. were considered as complicated injuries under this study.

\section{Observation and Results}

Out of 183 children injured in road traffic accident, higher proportion were reported in boys (151(82.51\%)) in compared to girls (32 (17.48\%)) so proportion of Male to Female is 4.7:1 Among 183 children, 36 children have simple injuries and 147 have sustained complicated injuries. In $143(78.14 \%)$ cases, incidence took place in rural area and $32(22.28 \%$ ) cases were noticed in urban area. The prevalence of road injury varied with socioeconomic condition and types of vehicle occupied by children for travel and for going to school. Children of different age group of rural population were more affected in compared to children reside in urban area. Children of 5-10 years age group were more involved followed by children of 10-15 years age group and then 15-18 years age group. In this study, the prevalence of road injury was highest among children who travel by two wheeler $(80.87 \%)$ in compared to travel by four wheeler $\&$ three wheeler $(6.55 \%$ each) and $6.01 \%$ cases were reported in pedestrian.

A vast majority of cases, $79(43.16 \%)$ was reported during daytime (8a.m. - 4 p.m.). The maximum number of road traffic accidents in children was reported between 8a.m.-12 p.m. (32.24\%) followed by 4p.m. - 8 p.m. (22.40. \%).

Under this study, injury sustained to the head and neck region of the body of children were more common $(28.96 \%)$ followed by multiple region injuries $(27.86 \%)$,) then chest injuries $(14.20 \%)$ and abdominal injuries (11.47\%). 
Table No:-1: Distribution of Road Traffic Accident (RTA) Injury According to Sex of Children

\begin{tabular}{|l|c|c|c|}
\hline Sex & $\begin{array}{c}\text { Simple } \\
\text { Injury }\end{array}$ & $\begin{array}{c}\text { Complicated } \\
\text { Injury }\end{array}$ & Total \\
\hline Male & 23 & 128 & $151(82.51 \%)$ \\
\hline Female & 13 & 19 & $32(17.48 \%)$ \\
\hline Total & 36 & 147 & 183 \\
\hline
\end{tabular}

Table No:-2: Distribution of Road Traffic Accident (RTA) Injury According to Place of Incidence

\begin{tabular}{|c|c|c|c|}
\hline Area & $\begin{array}{c}\text { Simple } \\
\text { Injury }\end{array}$ & $\begin{array}{c}\text { Complicated } \\
\text { Injury }\end{array}$ & Total \\
\hline Rural & 21 & 122 & $143(78.14 \%)$ \\
\hline Urban & 15 & 25 & $40(21.85 \%)$ \\
\hline Total & 36 & 147 & 183 \\
\hline
\end{tabular}

Table No:-3: Distribution of Road Traffic Accident (RTA) Injury in Children According to Different Age Group.

\begin{tabular}{|l|c|c|c|}
\hline $\begin{array}{l}\text { Age } \\
\text { (In years) }\end{array}$ & $\begin{array}{l}\text { Simple } \\
\text { Injury }\end{array}$ & $\begin{array}{c}\text { Complicated } \\
\text { injury }\end{array}$ & Total \\
\hline $1-5$ & 07 & 08 & $15(8.1 \%)$ \\
\hline $5-10$ & 06 & 54 & $60(32.78 \%)$ \\
\hline $10-15$ & 10 & 48 & $58(31.69 \%)$ \\
\hline $15-18$ & 13 & 37 & $50(27.32 \%)$ \\
\hline Total & 36 & 147 & 183 \\
\hline
\end{tabular}

Table No:-4: Distribution of Road Traffic Accident (RTA) Injury in Children According to Time of Accident.

\begin{tabular}{|l|c|c|c|}
\hline $\begin{array}{l}\text { Time of } \\
\text { Accident }\end{array}$ & $\begin{array}{c}\text { Simple } \\
\text { Injury }\end{array}$ & $\begin{array}{c}\text { Complicated } \\
\text { Injury }\end{array}$ & Total \\
\hline 8AM -12 AM & 11 & 48 & $59(32.24 \%)$ \\
\hline 12 PM - 4 PM & 03 & 17 & $20(10.92 \%)$ \\
\hline 4 PM - 8 PM & 13 & 28 & $41(22.40 \%)$ \\
\hline 8 PM - 12 AM & 01 & 17 & $18(09.83 \%)$ \\
\hline 12 AM- 4 AM & 03 & 18 & $21(11.47 \%)$ \\
\hline 4 AM -8 AM & 05 & 19 & $24(13.11 \%)$ \\
\hline
\end{tabular}

Table No:-5: Distribution of Road Traffic Accident (RTA) Injury in Children Using Different types of Vehicles.

\begin{tabular}{|l|c|c|c|}
\hline Types of Vehicle & $\begin{array}{c}\text { Simple } \\
\text { Injury }\end{array}$ & $\begin{array}{c}\text { Complicated } \\
\text { Injury }\end{array}$ & Total \\
\hline Pedestrian & 04 & 07 & $11(6.01 \%)$ \\
\hline Two Wheeler & 23 & 125 & $148(80.87 \%)$ \\
\hline Three Wheeler & 05 & 07 & $12(6.55 \%)$ \\
\hline Four Wheeler & 04 & 08 & $12(6.55 \%)$ \\
\hline
\end{tabular}

Table No:-6: Involvement of Different Body Organs in Children Affected in Road Traffic Accident

\begin{tabular}{|l|l|}
\hline Head & 53 \\
\hline Cervical Spine & 03 \\
\hline Chest & 26 \\
\hline Abdomen & 21 \\
\hline Pelvis & 08 \\
\hline Lower Limb & 21 \\
\hline Multiple organs & 52 \\
\hline
\end{tabular}

\section{Discussion}

Road traffic injuries (RTI) have been increasing over the past twenty years and the situation in India is worsening in concern to children. In 2015, WHO research studies showed that in India vehicle ownership is 6 per 100 person but road traffic fatalities are 11 per 100 person, while compared to other countries where much higher vehicle ownership rates than India but lower road traffic injuries cases were reported ${ }^{(6)}$. Research in several countries shows that, 90 percent of all road traffic accident are caused by human error and only a small portions caused by vehicle defect, poor road design and inadequate maintenance In many situation driver impairment is the most crucial component of road traffic accident worldwide $^{(7)}$. According to road safety data from transportation research and injury prevention programme (TRIPP) by Indian Institute of Technology Delhi in collaboration with WHO by Dinesh Mohan, Geetam Tiwari and Kavi Bhalla shows that vehicle population is increased to 140000 in 2015 from 20000 in $1970^{(8)}$ and prevalence of road traffic accidents is high among children of age group between 15 -18 years (31.8\%) and high involvement with passengers of two wheelers $(74.9 \%)$ in rural populations $(73.3 \%)$. The contributing factors for this prevalence could be road conditions in Indian rural areas, less knowledge of driving skill and negligence in following traffic rules, carrying children in front part of vehicles is more common in rural India. Road traffic accident was the most common and most neglected non-infectious cause of morbidity and mortality in children of India. 
The present study observed that most of road injury fatalities in children involved males in the age group of 5-15 years, most commonly affected were travellers in two wheelers. The present study found that the maximum number of casualties occurred between 8 am -12 Noon which is comparable with findings of other parts of India. Daytime is the usual working time in India for offices, business institutions and schools so there is greater exposure of people to vehicles at this time $^{(9)}$. Most schools close after $4 \mathrm{pm}$ therefore comparatively more children are present on the road at this time of the day thereby increasing their exposure to automobiles ${ }^{(10)}$. The time period between $4 \mathrm{pm}-8 \mathrm{pm}$ is generally the closing time of offices and more automobiles are present on the road during this time and moreover, this is also the time when children usually go out of home to play after completing their homework ${ }^{(11)}$. The findings of the present study are in accordance with the results of studies conducted nationally and internationally by WHO and government and non-government agencies.

\section{Conclusion}

The present study observed that most of the road injury fatalities in children involved males in the age group of 5-15 years.. Most commonly affected were two wheeler occupants of rural areas and most of the fatalities were seen during the daytime. To bring the case rate down, children, especially with rural background should be made aware about the importance of strict compliance to traffic rules and regulations. One of the best ways to do it is to include road safety issues in school curriculum. Those children who ride bicycles should be made to wear helmets as it is expected to reduce the severity of injury to the head. Drivers should avoid talking on mobile phones while on roads. The present study has highlighted the urgent need to frame road safety policies like separate lanes for different vehicles as the traffic in India in general and this region in particular consist of all kinds of automobiles including two wheelers, three wheelers and four wheelers thus increasing the chances of accidents. Installation of red lights and marking of zebra crossings on the roads particularly near schools and playgrounds would be a welcome decision. The government should also ensure that the vehicles must follow certain fixed speed limits at road where more children are exposed.

\section{References}

1. Aarts L, Schagen VI. Driving speed and the risk of road crashes: a review. Accident Analysis Prevention. 2006;38:215-24.

2. Dandona R, Kumar GA, Aerating S, Dandona L. Road use pattern and risk factors for non-fatal road traffic injuries among children in urban India. Injury. 2011;42(1):97-103.

3. Census of India. Vital statistics, SRS statistical report 2011. Population composition.

4. Nantulya MV, Reich MR. The neglected epidemic: Road traffic injuries in developing countries. BMJ. 2002;324: 1139-41

5. Crime in India, National Crime Records Bureau. Ministry of home Affairs, Government of India 2015.

6. Delgado J, Ramirez-Cardich ME, Gilman $\mathrm{RH}$, et al. Risk factors for burns in children: crowding poverty, and poor maternal education. Inj Prev 2002;8

7. Accidental deaths and suicides in India 2014. New Delhi. Available at http:// ncrb.nic.in/ StatPublications/ ADSI/ ADSI2014/adsi-2014\%2 Ofull\% 20report.pdf. Accessed on 13 July 2016.

8. W.H.O. Global status report on road safety 2015. Geneva: World Health Organization. 2015.

9. Mohan D. Road accidents in India. J Int Asso Traffic Safety Sci. 2009; 33:75-9.

10. Gururaj G, Uthkarsh PS, Rao GN, Jayaram AN, Panduranganath V. Burden, pattern and outcomes of road traffic injuries in a 
rural district of India. Int $\mathrm{J}$ Inj Contr Saf Promot. 2016;23(1):64-71.

11. Third African Road Safety congress. Available at http://www.worldbank.org/transport/public ate/b28. Accessed on 13 July 2016. 